\title{
The effects of early coronary patency on the evolution of myocardial infarction: a prospective arteriographic study
}

\author{
ADAM D TIMMIS, BRIAN GRIFFIN, JONATHAN C P CRICK, \\ DAVID J NELSON, EDGAR SOWTON \\ From the Department of Cardiology, Guy's Hospital, London with statistical analysis by Data Analysis and \\ Research Limited, New Lanark, Lanarkshire
}

SUMMARY The effects of early spontaneous coronary patency on the evolution of myocardial infarction were evaluated in 41 patients. They had coronary arteriography (mean (SEM)) $3 \cdot 1(0 \cdot 2)$ hours after the onset of chest pain with repeat studies 90 minutes and three days later. In $12(29 \%)$ patients the infarct related coronary artery was patent at the first arteriogram (group 1). A further 10 patients, nine of whom received thrombolytic treatment, showed early recanalisation of the infarct related coronary artery within 90 minutes of treatment (group 2). In the remainder the infarct related coronary artery was persistently occluded (group 3 ). Baseline values for infarct location, the sum of ST elevation in all leads, QRS scores, and serum creatine kinase activity did not permit discrimination between the groups. Nevertheless, patterns of ST segment change and enzyme release in group 1 were closely similar to those that occurred in response to thrombolysis in group 2. Thus compared with group 3, groups 1 and 2 showed earlier $50 \%$ reduction in the sum of peak ST elevation in all leads and earlier peaking of serum creatine kinase activity. Importantly, creatine kinase release was significantly attenuated in group 1, rising to a peak serum activity (mean (SEM)) of only 1242 (415) IU/1. Analysis of angiographic left ventricular ejection fractions at three days indicated limitation of infarct size in groups 1 and 2 compared with group 3. Mean (SEM) ejection fraction, however, was best preserved in group $1(62(6) \%)$ and in this group the frequency of non-Q wave infarction was higher than in groups 2 and 3.

Thus in patients who present with a patent infarct related coronary artery early during infarction: (a) there is a reduction in the pattern of infarct size as reflected by attenuation of release of creatine kinase, preservation of left ventricular ejection fraction, and a relatively high frequency of non- $Q$ wave infarction; (b) patterns of ST segment change and creatine kinase release resemble those that occur after successful thrombolytic treatment, suggesting that early coronary patency is the result of spontaneous recanalisation of a previously occluded artery.

The full transmural extent of myocardial infarction may not be established for six hours or more after thrombotic coronary artery occlusion. ${ }^{1}$ Thus early recanalisation of the occluded coronary artery within this period may limit the ultimate extent of infarction by permitting reperfusion of the threatened myocardium. ${ }^{2-4}$ This accounts for the beneficial

Requests for reprints to Dr Adam D Timmis, Department of Cardiology, Guy's Hospital, St Thomas' Street, London SE1 9RT.

Accepted for publication $1 \mathrm{June} 1987$ effects of thrombolytic treatment on infarct size ${ }^{56}$ and hospital survival ${ }^{7-9}$ in patients treated early after the onset of symptoms. In a considerable proportion of cases, however, recanalisation occurs spontaneously either owing to unsustained spasm (spasm may be necessary for clot stabilisation) or to endogenous thrombolysis. ${ }^{10}$ Nevertheless, the timing of spontaneous recanalisation is likely to be critical and the data of de Wood et al indicate that in many cases it occurs too late to permit clinically significant myocardial salvage. ${ }^{10}$ Thus although a number of investigators have shown that patency of 
the infarct related coronary artery late after infarction is associated with more limited myocardial damage, ${ }^{1-13}$ retrospective data of this type do not accurately identify the important subgroup in whom recanalisation occurs early enough to influence the evolution of infarction.

The present study is a prospective evaluation of patients with early patency of the infarct related coronary artery. Coronary anatomy was defined by arteriography during the acute phase of myocardial infarction. The effects of early coronary patency on the evolution of infarction were examined with particular reference to enzyme release, electrocardiographic changes, and infarct size.

\section{Patients and methods}

\section{PATIENTS}

Forty one patients (mean (SD) age 56 (9) years, 5 women and 36 men) were studied over a period of 18 months. All but one of these patients had been included in a randomised study of anisoylated plasminogen streptokinase activator complex, the results of which have been reported. ${ }^{14}$ Patients with symptoms of acute myocardial infarction of less than six hours' duration were considered for entry. The site of the infarct was anterior in 21 cases and inferior in 20 cases. We studied only patients with ST segment elevation of $>0.1 \mathrm{mV}$ in one or more standard leads or $>0.2 \mathrm{mV}$ in one or more precordial leads that persisted despite treatment with nitrates. Exclusion criteria were a history of cerebrovascular accident, operation, or active peptic ulceration within the previous three months; severe hypertension ( $>200 / 120 \mathrm{~mm} \mathrm{Hg}$ ); or heart failure or external cardiac massage. All patients gave informed verbal consent for inclusion in the study which was approved by the hospital ethics committee.

\section{STUDY DESIGN}

After documentation of the degree of patency of the infarct related coronary artery by arteriography the patients were randomised to intravenous treatment. Twenty received anisoylated plasminogen streptokinase activator complex $30 \mathrm{mg}$ and 20 received placebo. One patient was not randomised at the request of the referring physician. The degree of patency was reassessed by repeat coronary arteriography 90 minutes after treatment. Heparin sodium (1000 units/hour) was given by intravenous infusion four hours after catheterisation and was continued with dosage adjustments until completion of the final coronary arteriogram approximately three days later. During the study other drugs routinely used for the management of myocardial infarction were not withheld.
CORONARY ARTERIOGRAPHY

The first coronary arteriogram and the 90 minute follow up study were performed by modified Judkins' technique in a side room attached to the coronary care unit. Images were recorded on video tape. The three day coronary arteriogram (together with left ventricular angiography) was performed in the cardiac catheterisation laboratory with multiple projections recorded on cine film.

In one patient in whom a persistently occluded coronary artery was demonstrated equipment failure prevented recording of the acute phase coronary arteriograms on video tape. In a further four patients cardiac catheterisation at three days was not performed, because of clinical deterioration or death in three cases or the request of the referring physician in another one case. The remainder of the arteriographic recordings were complete and were reported by an independent cardiologist who is not an author of this paper. Patency was graded according to the criteria of the TIMI study group. ${ }^{15}$ Recanalisation was defined as a change from TIMI grade 0 or 1 to 2 or 3 . Left ventricular ejection fraction was calculated by hand digitisation of end systolic and end diastolic right anterior oblique angiographic frames with a microcomputer system (Commodore).

\section{ELECTROCARDIOGRAPHIC AND ENZYMATIC DATA}

A 12 lead electrocardiogram was recorded on admission, immediately before coronary arteriography, and again one, two, six, and 24 hours later. Recordings thereafter were performed every 24 hours for three days. All electrocardiograms were recorded at the standard calibration of $1 \mathrm{mV} / \mathrm{cm}$ at a paper speed of $25 \mathrm{~mm} / \mathrm{second}$. ST segment elevation was measured 0.04 seconds after the end of the QRS complex. The sum of the ST segment elevation in all leads ( $S$ ST) was calculated. The peak $\sum S T$ elevation for each patient was defined as the maximum SST elevation within six hours of the first coronary arteriogram. The electrocardiograms recorded at the time of hospital admission and at three days were scored according to the 29 point system described by Palmeri et $a l^{16}$ on the basis of the $Q$ and $R$ wave duration and $R$ to $Q$ and $R$ to $S$ amplitude ratios. All electrocardiographic data were complete except for QRS scores at three days in the three patients who died.

Serum creatine kinase activity was measured on admission to the hospital and thereafter at every four hours for 36 hours. A final measurement was made at 48 hours. The upper reference limit for our laboratory is $200 \mathrm{IU} / \mathrm{L}$. One patient (group 1) was excluded from the enzyme analysis because of severe 
but ultimately reversible rhabdomyolysis in the leg which complicated the acute catheter procedure. In the remaining patients $82 \%$ of the projected measurements were obtained.

\section{STATISTICAL ANALYSIS}

All averaged values are expressed as mean (SEM). The distribution of discrete variables between groups was compared by $\chi^{2}$ testing. The median values between groups were compared by the MannWhitney test (non-parametric). Because there were three groups a total of only two comparisons was permitted. Those chosen were combined data for groups 1 and 2 versus 3 and the individual data for group 1 versus that for 2 . ST segment and $T$ wave changes were timed from the onset of chest pain. The rates at which $\sum S T$ elevation resolved were compared on the basis of time from onset of chest pain to $50 \%$ of peak $\sum \mathrm{ST}$ elevation or to a $\sum \mathrm{ST}$ elevation of $\leqslant 0.3 \mathrm{mV}$ or less, whichever occurred first.

\section{Results}

CORONARY ARTERIOGRAPHY: ACUTE FINDINGS Coronary arteriography was performed $3 \cdot 1(0 \cdot 2)$ hours after the onset of chest pain and was repeated 90 minutes later at $4.6(0.2)$ hours. In none of the patients was there significant collateralisation of the infarct related coronary artery. Three subgroups were identified on the basis of the acute arteriographic findings. Group 1 was made up of 12 patients with TIMI grade 2 or 3 patency of the infarct related coronary artery at the first study. In each case, despite critical ( $>70 \%$ ) luminal stenoses, the infarct related coronary artery remained patent at the follow up study. Group 2 was made up of 10 patients in whom the infarct related coronary artery was occluded at the first study with early recanalisation at the follow up study. Group 3 was made up of 19 patients in whom the infarct related coronary artery was occluded at the first study and in whom early recanalisation did not occur.

\section{CORONARY ARTERIOGRAPHY: LATE FINDINGS} Approximately three days (65.6 (4.2) hours) after infarction, patency of the infarct related coronary artery was maintained in all group 1 patients, although only four had received anisoylated plasminogen streptokinase activator complex. In group 2 reocclusion occurred in one patient who had received anisoylated plasminogen streptokinase activator complex but patency was maintained in the remainder. In group 3 late recanalisation occurred in four patients, three of whom had received anisoylated plasminogen streptokinase activator complex.

\section{BASELINE VARIABLES (Table)}

There were no important differences between the groups in infarct location, history of previous infarction, or time from onset of chest pain to coronary arteriography. Baseline values for serum. creatine kinase, $\sum S T$ elevation, and QRS scores were also similar. Only the treatment randomisation showed significant differences. Thus $90 \%$ of group 2 received anisoylated plasminogen streptokinase activator complex compared with $33 \%$ and $37 \%$ of groups 1 and 3 respectively.

\section{SERUM CREATINE PHOSPHOKINASE}

Serial creatine kinase measurements during the $\mathbf{4 8}$ hours after hospital admission showed an increase to more than twice the upper reference limit in every patient except one (group 1). Peak values occurred significantly earlier in groups 1 and 2 than in group $3(13.6(1.5)$ versus $24 \cdot 1(1 \cdot 1)$ hours, $p<0.01$ ) (fig 1 ). Although there was no significant difference in the time to peak serum concentrations between groups 1 and 2 , creatine kinase release was significantly

Table Baseline variables (mean (SEM))

\begin{tabular}{|c|c|c|c|}
\hline & $\begin{array}{l}\text { Group 1 } \\
\text { (Patent IRCA) }\end{array}$ & $\begin{array}{l}\text { Group } 2 \\
\text { (Patent IRCA) }\end{array}$ & $\begin{array}{l}\text { Group } 3 \\
\text { (Occluded IRCA) }\end{array}$ \\
\hline Number of patients & 12 & 10 & 19 \\
\hline History of previous infarction (n) & 1 & 1 & 2 \\
\hline $\begin{array}{l}\text { Anterior } \\
\text { Inferior }\end{array}$ & $\begin{array}{l}58 \\
42\end{array}$ & $\begin{array}{l}60 \\
40\end{array}$ & $\begin{array}{l}42 \\
58\end{array}$ \\
\hline $\begin{array}{l}\text { Anisoylated plasminogen streptokinase } \\
\text { activator complex }(\%)\end{array}$ & 33 & 90 & 37 \\
\hline $\begin{array}{l}\text { Coronary arteriography (hours after } \\
\text { onset of chest pain) }\end{array}$ & $3.2(0.4)$ & $2.8(0.4)$ & $3.3(0.3)$ \\
\hline $\begin{array}{l}\text { ¿ST elevation (mV) } \\
\text { Creatine kinase (IU/l) } \\
\text { QRS score }\end{array}$ & $\begin{array}{c}1 \cdot 4(0 \cdot 3) \\
265(90) \\
3(1)\end{array}$ & $\begin{array}{c}1 \cdot 7(0 \cdot 3) \\
165(60) \\
4(1)\end{array}$ & $\begin{array}{c}1 \cdot 2(0 \cdot 3) \\
148(26) \\
3(1)\end{array}$ \\
\hline
\end{tabular}

IRCA, infarct related coronary artery.

Conversion: traditional units to SI units-Creatine kinase: I IU/l $=16.7 \times 10^{-3} \mu \mathrm{kat} / \mathrm{l}$. 
348



Fig 1 Serum creatine kinase (CK) measurements during the $51(0.2)$ hours after the onset of chest pain. Points and bars are mean values (SE) for groups 1 to 3.

attenuated in group 1 , rising to a peak serum concentration of only $1242(415) \mathrm{IU} / 1(\mathrm{p}<0.05)$. Infarct location did not influence the enzymatic data.

\section{ST SEGMENT CHANGES}

Serial electrocardiogram recordings showed that ¿ST elevation was resolving during the first five hours after the onset of chest pain in groups 1 and 2 (fig 2). In group 3, on the other hand, resolution was delayed to between five and nine hours. Thus the time to $50 \%$ reduction in $\sum \mathrm{ST}$ elevation was significantly shorter in groups 1 and 2 than in group $3(8.1(1.7)$ versus $11.9(2 \cdot 4)$ hours, $p<0.01)$. The difference between groups 1 and 2 was not significant. Infarct location did not influence the changes in $\Sigma S T$ elevation.

\section{INFARCT SIZE AT THREE DAYS}

Angiographic left ventricular ejection fraction three days after admission was well preserved in groups 1 and 2 at $62(6)$ and $56(6) \%$, respectively (fig 3 ). In group 3 the left ventricular ejection fraction was significantly lower $(45(4) \% ; p<0.05)$. QRS scores showed a similar trend; however the differences between groups were not significant. Nevertheless, the frequency of non- $Q$ wave infarction was significantly higher in group 1 than in groups 2 and $3(42 \%$ versus $10 \%$ and $0 \% ; p<0.05)$.

\section{Discussion}

In this study coronary arteriography during the acute phase of myocardial infarction confirmed that a considerable proportion of patients have a patent infarct related coronary artery at the time of hospital admission. This is an important subgroup because, compared with patients in whom the infarct related coronary artery remains occluded, infarct size is
Timmis, Griffin, Crick, Nelson, Sowton



Fig 2 SST elevation during the $27(0 \cdot 2)$ hours after the onset of chest pain. Points and bars are mean values (SE) for groups 1 to 3.
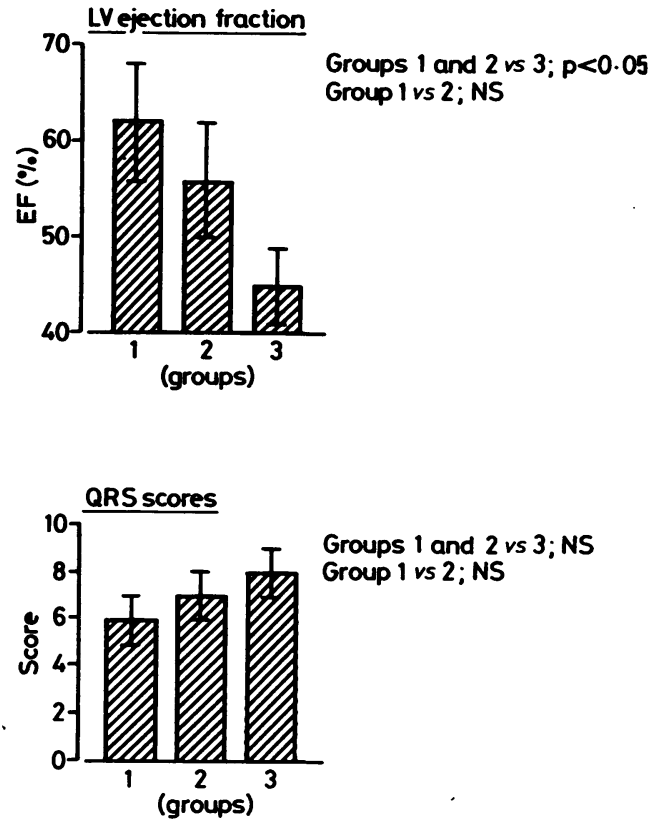

Fig 3 Angiographic left ventricular ( $L V$ ) ejection fraction and $Q R S$ score three days after admission. Mean values $(S E)$ are shown for groups 1 to 3.

reduced as judged by attenuation of creatine kinase release, a high frequency of non- $Q$ wave infarction, and preservation of left ventricular ejection fraction at three days.

A simple non-invasive method for early identification of patients who present with a patent infarct related coronary artery would be of considerable clinical value, enabling the selection of specific treatment aimed at maintaining coronary patency. Our data, however, indicate that early 
identification is not possible on the basis of electrocardiographic and enzymatic criteria obtained at the time of presentation. Nevertheless, serial analysis of ST segment shifts and serum creatine kinase values shows a pattern of changes that has striking similarities to patients in whom thrombolytic treatment leads to early recanalisation of the infarct related coronary artery. In both groups ST segment elevation resolves more rapidly and serum creatine kinase peaks earlier than in patients with persistent occlusion of the infarct related coronary artery. Importantly, however, creatine kinase release is significantly attenuated in patients who present with a patent infarct related coronary artery, suggesting that myocardial damage may be less extensive in this subgroup. ${ }^{1718}$

Further evidence for limitation of infarct size in patients with early patency of the infarct related coronary artery is provided by the data at three days. These show that patients of this type have a higher frequency of non- $Q$ wave infarction, ${ }^{1920}$ and better preservation of left ventricular ejection fraction ${ }^{21}$ than patients in whom the infarct related coronary artery is persistently occluded. Thus the mean value for ejection fraction in patients who presented with a patent infarct related coronary artery was greater than $60 \%$ despite a small preponderance of anterior infarcts within the subgroup, which might have been expected to bias the data towards more extensive myocardial damage. ${ }^{2122}$ Left ventricular ejection fraction was also well preserved in patients who showed early coronary recanalisation after thrombolytic treatment. Persistent occlusion of the infarct related coronary artery, on the other hand, was associated with significant depression of left ventricular ejection fraction at three days. These trends were to some extent reflected by the QRS scores, which tended to be lower in patients who presented with, or who developed, early patency of the infarct related coronary artery. Nevertheless, not all investigators have found a good correlation between QRS scores and left ventricular ejection fraction in patients with acute myocardial infarction $^{23-25}$; this may explain why the differences between subgroups in the present study were not statistically significant.

Prospective arteriographic studies defining relations between early spontaneous coronary patency, enzyme release, electrocardiographic changes, and infarct size have not previously been reported. Ong et al inferred spontaneous coronary recanalisation in a subgroup of patients who showed early peaking of serum creatine kinase and improvement in radionuclide left ventricular ejection fraction..$^{26}$ The only available arteriographic studies, however, have been retrospective, based upon documentation of coronary patency late after myocardial infarction. ${ }^{27-29}$ Studies of this type must be interpreted cautiously because in an indeterminate number of cases recanalisation will have occurred too late to exert an appreciable influence on the evolution of infarction. Nevertheless, the retrospective analysis reported by Hackworthy et $\mathrm{al}^{27}$ shows some concordance with our own data. These workers found early peaking of serum creatine kinase activity and rapid resolution of ST segment elevation in patients later shown to have a patent infarct related coronary artery. When compared with patients in whom the infarct related coronary artery was occluded, however, the differences were less pronounced than in the present study and showed greater variability within subgroups. This is probably related to the inclusion of patients with late recanalisation within the subgroup with patency of the infarct related coronary artery. This may explain why these workers were not able to demonstrate significant differences in infarct size (as reflected by creatine kinase release and ejection fraction) between patients with and without patency of the infarct related coronary artery.

Our data demonstrated a significantly higher frequency of non- $Q$ wave myocardial infarction in the patients who presented with a patent infarct related coronary artery (group 1). In two recent studies of non- $Q$ wave myocardial infarction, the time to peak serum creatine kinase was shorter than in $Q$ wave infarction and the frequency of patency of the infarct related coronary artery (demonstrated by predischarge arteriography at 11 (3) days) was higher. ${ }^{28} 29$ De Wood et al have also demonstrated a high frequency $(74 \%)$ of coronary patency in patients catheterised within 24 hours of the onset of symptoms who went on to evolve non- $Q$ wave myocardial infarction. ${ }^{30}$ Direct comparisons with our own data, however, are difficult because in only one of these studies was early ST segment elevation an inclusion criterion. ${ }^{29}$ Nevertheless, the findings are in general agreement and have led to speculation that the pathogenesis of non- $Q$ wave myocardial infarction may involve spontaneous coronary recanalisation. This certainly provides the most plausible mechanism for early coronary patency in the present study, unless infarction was the result of critical reductions of coronary flow without complete arterial occlusion. Thus every patient in group 1 presented with pronounced ST segment elevation suggesting recent coronary occlusion. ${ }^{31}$ Moreover, the rapid resolution of ST segment elevation was closely similar to that which occurred in patients who had recanalisation after thrombolytic treatment. It is possible to speculate, therefore, that early 
coronary patency in group 1 was the result of endogenous thrombolysis occurring betore coronary arteriography. Unsustained spasm may also have been a contributory factor, particularly since all patients in the study received nitrate treatment at admission to the hospital.

Acute myocardial infarction with early patency of the infarct related coronary artery is not uncommon. In the present series it was found in $29 \%$ of the patients, all of whom underwent coronary arteriography less than six hours after the onset of chest pain. Importantly, our data have demonstrated that within this subgroup with early coronary patency, myocardial damage is often relatively limited even when compared with patients treated successfully with thrombolytic agents. Indeed, although thrombolytic treatment is now recommended for coronary recanalisation in acute myocardial infarction, this may not be appropriate when the infarct related coronary artery is already patent. More work is required to define the mechanisms of myocardial infarction in this subgroup and to identify early non-invasive diagnostic criteria. Ultimately this may permit the development of specific treatment strategies directed at maintaining coronary patency and preventing progression to total coronary occlusion.

We thank Dr David de Bono, Department of Cardiology, Royal Infirmary of Edinburgh, who reported on all the coronary arteriograms obtained in this study.

\section{References}

1 Reimer KA, Jennings RB. The "wavefront phenomenon" of myocardial ischemic cell death. II. Transmural progression of necrosis within the framework of ischemic bed size (myocardium at risk) and collateral flow. Lab Invest 1979;40:633-44.

2 Maroko PR, Libby P, Ginks WR, et al. Coronary artery reperfusion. I. Early effects on local myocardial function and the extent of myocardial necrosis. J Clin Invest 1972;51:2717-23.

3 Reimer KA, Lowe JE, Rasmussen MM, Jennings RB. The wavefront phenomenon of ischemic cell death. I. Myocardial infarct size versus duration of coronary occlusion in dogs. Circulation 1977;56:786-94.

4 Baughman KL, Maroko PR, Vatner SF. Effects of coronary artery reperfusion on myocardial infarct size and survival in conscious dogs. Circulation 1981;63:317-23.

5 Smalling RW, Fuentes F, Mathews MW, et al. Sustained improvement in left ventricular function and mortality by intracoronary streptokinase administration during evolving myocardial infarction. Circulation 1983;68:131-8.
6 Simoons ML, Serruys PW, Van den Brand M, et al. Early thrombolysis in acute myocardial infarction: limitation of infarct size and improved survival. $\mathrm{J} \mathrm{Am}$ Coll Cardiol 1986;7:729-42.

7 European Co-operative Study Group for Streptokinase Treatment in Acute Myocardial Infarction. Streptokinase in acute myocardial infarction. $N$ Engl $J$ Med 1979;301:797-802.

8 Kennedy JW, Ritchie JL, Davis KB, Fritz JK. Western Washington randomized trial of intracoronary streptokinase in acute myocardial infarction. $N$ Engl J Med 1983;309:1477-82.

9 Gruppo Italiano per lo Studio della Streptochinasi nell' Infarcto (GISSI). Effectiveness of intravenous thrombolytic treatment in acute myocardial infarction. Lancet 1986;i:397-401.

10 De Wood MA, Spores J, Notske R, et al. Prevalence of total coronary occlusion during the early hours of transmural myocardial infarction. $N$ Engl J Med 1980;303:897-902.

11 Marmor A, Ludbrook PA, Sobel BE, Roberts R. Vascular determinants of early recurrent myocardial infarction [Abstract]. Am J Cardiol 1981;47:418.

12 Nygaard TW, Gibson RS, Craddock GB, Sirowatka J, Crampton RS, Beller GA. Comparison of patent and occluded infarct-related vessels at 2 weeks postmyocardial infarction in patients not receiving thrombolytic therapy [Abstract]. J Am Coll Cardio 1983;1:579.

13 Hackworthy RA, Vogel MB, Harris PJ. Influence of infarct artery patency on the relation between initial ST segment elevation and final infarct size. $\mathrm{Br}$ Heart $J$ 1986;56:222-5.

14 Timmis AD, Griffin B, Crick JCP, Sowton E Anisoylated plasminogen streptokinase activator complex in acute myocardial infarction: a placebo controlled, arteriographic, coronary recanalization study. J Am Coll Cardiol 1987;10:205-10.

15 The TIMI Study Group. The thrombolysis in myocardial infarction (TIMI) trial; phase I findings. N Engl J Med 1985;312:932-6.

16 Palmeri ST, Harrison DG, Colele FR, et al. A QRS scoring system for assessing left ventricular function after myocardial infarction. $N \mathrm{Engl} J \mathrm{Med}$ 1982;306:4-9.

17 Shell WE, Kjekshus JK, Sobel BE. Quantitative assessment of the extent of myocardial infarction in the conscious dog by means of analysis of serial changes in creatine phosphokinase activity. $J$ Clin Invest 1971;50:2614-25.

18 Bleifield WH, Hanrath P, Mathey D. Serial CPK determinations for evaluation of size and development of acute myocardial infarction. Circulation 1976;53 (suppl I):108-11.

19 Spodick DH. Q-wave infarction versus $S-T$ infarction. Nonspecificity of electrocardiographic criteria for differentiating transmural and nontransmural lesions. Am J Cardiol 1983;51:913-5.

20 Nicod P, Corbett JR, Sanford F, et al. Comparison of the influence of acute transmural and nontransmural myocardial infarction on ventricular function. $\mathrm{Am}$ Heart $J$ 1984;107:28-34. 
21 Shah BK, Pichler M, Berman DS, Singh BN, Swan HJ. Left ventricular ejection fraction determined by radionuclide ventriculography in early stages of first transmural myocardial infarction: relation to shortterm prognosis. Am J Cardiol 1980;45:542-6.

22 Norris RM, Caughey DE, Deeming LW, Mercer CJ, Scott PJ. Coronary prognostic index for predicting survival after recovery from acute myocardial infarction. Lancet 1970;ii:485-7.

23 De Pace NL, Iskandrian AS, Hakki A, Kane SA, Segal BL. Use of QRS scoring and thallium-201 scintigraphy to assess left ventricular function after myocardial infarction. Am J Cardiol 1982;50:1262-8.

24 Young SG, Abouantoun S, Savvides M, Madsden EB, Froelicher V. Limitations of electrocardiographic scoring systems for estimations of left ventricular function. J Am Coll Cardiol 1983;1:1479-88.

25 Fioretti P, Brower RW, Lazzeroni E, et al. Limitations of a QRS scoring system to assess left ventricular function and prognosis at hospital discharge after myocardial infarction. Br Heart $J$ 1985;53:248-52.

26 Ong L, Reiser P, Coromilas J, Scherr L, Morrison J. Left ventricular function and rapid release of creatine for spontaneous reperfusion. $N$ Engl J Med 1983; 309:1-6.

27 Hackworthy RA, Vogel MB, Harris PJ. Relationship between changes in ST segment elevation and patency of the infarct-related coronary artery in acute myocardial infarction. Am Heart $J$ 1986;112:279-84.

28 Gibson RS, Beller GA, Gheorghiade $M$, et al. The prevalence and clinical significance of residual myocardial ischemia 2 weeks after uncomplicated non- $Q$ wave infarction: a prospective natural history study. Circulation 1986;73:1186-98.

29 Huey BL, Gheorghiade M, Crampton RS, et al. Acute non- $Q$ wave myocardial infarction associated with early ST segment elevation: evidence for spontaneous coronary reperfusion and implications for thrombolytic trials. J Am Coll Cardiol 1987;9:18-25.

30 De Wood MA, Stifter WF, Simpson CS, et al. Coronary arteriographic findings soon after non- $Q$ wave myocardial infarction. $N$ Engl $J$ Med 1986;315:417-23.

31 Pardee HEB. An electrocardiographic sign of coronary artery obstruction. Arch Intern Med 1920;26:244-57. 